\title{
Effects of footwear on medial compartment knee osteoarthritis
}

\author{
Meika A. Fang, MD; ${ }^{1-2 *}$ Connie E. Taylor, MD; ${ }^{1}$ Aksone Nouvong, DPM; ${ }^{1-2}$ Sulabha Masih, MD; ${ }^{1-2}$ \\ Kaly C. Kao; ${ }^{1-2}$ Karen L. Perell, PhD, RKT ${ }^{1,3}$ \\ ${ }^{1}$ Department of Veterans Affairs Greater Los Angeles Healthcare System, Los Angeles, CA; ${ }^{2}$ University of California, \\ Los Angeles, David Geffen School of Medicine, Los Angeles, CA; ${ }^{3}$ Departments of Kinesiology and Health Science, \\ California State University, Fullerton, CA
}

\begin{abstract}
This pilot study investigated whether lateral-wedge insoles inserted into shock-absorbing walking shoes altered joint pain, stiffness, and physical function in patients with symptomatic medial compartment knee osteoarthritis (OA). Twenty-eight subjects wore full-length lateral-wedge insoles with an incline of $4^{\circ}$ in their walking shoes for 4 weeks. Pain, stiffness, and functional status were measured with the Western Ontario and McMaster Universities (WOMAC) Osteoarthritis Index at baseline and 4 weeks postintervention. Significant improvements were observed in all three WOMAC subscales (pain, stiffness, and function). Pain scores were significantly reduced for the most challenging activity—stair climbing. Subjects wore insoles daily and tolerated them well. The results of this study indicated that lateral-wedge insoles inserted into shock-absorbing walking shoes are an effective treatment for medial compartment knee OA.
\end{abstract}

Key words: functional status, knee, lateral-wedge insoles, orthoses, osteoarthritis, pain, rehabilitation, shock-absorbing shoes, stair climbing, stiffness, varus.

\section{INTRODUCTION}

Knee osteoarthritis (OA) is a disease common in older adults that can result in significant disability because of pain, stiffness, and loss of joint motion. Current treatment is aimed at minimizing pain, maintaining or improving joint mobility, and decreasing functional impairment. Although the pathogenesis of knee OA is not well understood, biomechanical stresses that affect the articular cartilage and subchondral bone have been impli- cated as important inciting factors [1-3]. During the midstance phase of gait, about 60 to 80 percent of the load is distributed through the medial compartment of the normal knee [4], which is one of the reasons knee OA frequently involves the medial compartment. Varus angulation deformity may occur in medial compartment knee $\mathrm{OA}$ and contribute to the progression of OA by causing increased load to the medial knee compartment, with subsequent damage to the articular cartilage and subchondral bone in that area [5].

Clinicians have used surgical wedge osteotomy for many years to correct varus angulation by shifting weight away from the diseased knee compartment [6]. An alternative nonoperative approach has been to realign the weight-bearing load through footwear modification. Shoe modifications, such as lateral-wedge insoles or shockabsorbing shoes with insoles, have been recommended for conservative therapy of mild knee OA [7-8]. Little objective data exist, however, regarding the effects of lateralwedge insoles on clinical parameters such as pain and

\footnotetext{
Abbreviations: NSAID $=$ nonsteroidal anti-inflammatory drug, $\mathrm{OA}=$ osteoarthritis, $\mathrm{SD}=$ standard deviation, $\mathrm{VA}=$ Department of Veterans Affairs, VAS = visual analog scale, WOMAC $=$ Western Ontario and McMaster Universities (Osteoarthritis Index).

* Address all correspondence to Meika A. Fang, MD; GRECC 11G, 11301 Wilshire Blvd, Los Angeles, CA 90073; 310-268-4503; fax: 310-268-4250.

Email: meika.fang@med.va.gov

DOI: 10.1682/JRRD.2005.10.0161
} 
functional status in patients with symptomatic medial compartment knee OA [9-10]. One randomized controlled study showed that subjects with medial compartment knee OA decreased nonsteroidal anti-inflammatory drug (NSAID) intake when they wore bilateral lateralwedge insoles but did not report any change in pain, stiffness, or function as measured by the Western Ontario and McMaster Universities (WOMAC) Osteoarthritis Index [11]. Women with medial compartment knee OA who wore bilateral lateral-wedge insoles with elastic strapping of the subtalar joint had a significant decrease in femorotibial angle and visual analog scale (VAS) score for subjective knee pain and an improvement in Lequesne index scores (a measure of disease severity) [12]. These changes were not observed in women who wore traditional shoeinserted lateral-wedge insoles. A lateral-wedge insole reduces peak knee varus torque, external varus moment, and lateral thrust in patients with knee OA, which may be some of the mechanisms by which this insert reduces pain in knee OA [13-15].

In this uncontrolled pilot study, we investigated the short-term effects of full-length lateral-wedge insoles combined with shock-absorbing shoes on pain and function in the treatment of symptomatic medial compartment knee OA.

\section{METHODS}

\section{Subjects}

Twenty-eight community-dwelling individuals (mean age \pm standard deviation [SD] $=67 \pm 11 \mathrm{yr}$ ) who fulfilled American College of Rheumatology criteria [16] for knee OA were recruited for this study through flyers distributed in outpatient clinics of the Department of Veterans Affairs (VA) Greater Los Angeles Healthcare System and community newspaper advertisements. All subjects had grade 2 or higher Kellgren-Lawrence radiographic severity of tibiofemoral $\mathrm{OA}$ in the standing anteroposterior view [17], pain of at least 30 on a 0 to $100 \mathrm{~mm}$ VAS, and pain in the medial compartment of the knee for most days in the past month. Exclusion criteria were history of knee trauma or surgery, including arthroscopic surgery in the past 6 months; neurological disease; injury to or amputation of the lower-limb joints; history of other types of arthritis; symptomatic spine, hip, ankle, or foot disease; intra-articular steroid injection in the past 3 months; or hyaluronic acid injection in the last 9 months. Subject characteristics are reported in Table 1.
The index knee was identified as the painful OA knee at baseline, although seven subjects had bilaterally painful knees. Subjects wore lateral-wedge insoles on the side with knee pain and neutral-wedge insoles on the side without knee pain; a standard configuration recommended by healthcare practitioners when prescribing lateralwedge insoles for patients with symptomatic medial compartment knee OA. The subjects who reported bilateral knee pain wore lateral-wedge insoles bilaterally.

The study was approved by the VA Greater Los Angeles Healthcare System Institutional Review Board, and informed consent was obtained from all subjects before they were enrolled in the study. This clinical trial was registered in the National Library of Medicine's clinical trials registry (http://www.clinicaltrials.gov).

Table 1.

Subject characteristics $(N=28)$.

\begin{tabular}{|c|c|c|c|}
\hline Characteristic & Mean \pm SD & Frequency* & $\% *$ \\
\hline Age (yr) & $67 \pm 11$ & - & - \\
\hline \multicolumn{4}{|l|}{ Sex } \\
\hline Male & - & 18 & 64 \\
\hline Female & - & 10 & 36 \\
\hline \multicolumn{4}{|l|}{ Race/Ethnicity } \\
\hline Caucasian & - & 20 & 72 \\
\hline African American & - & 4 & 14 \\
\hline Other (Hispanic, Asian) & - & 4 & 14 \\
\hline Body Mass Index $\left(\mathrm{kg} / \mathrm{m}^{2}\right)$ & $27.6 \pm 5.2$ & - & - \\
\hline \multicolumn{4}{|l|}{ Index Knee } \\
\hline Right & - & 9 & 32 \\
\hline Left & - & 12 & 43 \\
\hline Bilateral & - & 7 & 25 \\
\hline \multicolumn{4}{|l|}{ Kellgren-Lawrence Grade ${ }^{\dagger}$} \\
\hline II & - & 10 & 36 \\
\hline III & - & 10 & 36 \\
\hline IV & - & 8 & 28 \\
\hline \multicolumn{4}{|l|}{ Concurrent Medications ${ }^{\ddagger}$} \\
\hline $\begin{array}{l}\text { Nonsteroidal anti-inflammatory } \\
\text { drugs }\end{array}$ & - & 13 & 46 \\
\hline $\begin{array}{l}\text { Acetaminophen-opioid } \\
\text { combination }\end{array}$ & - & 3 & 11 \\
\hline Acetaminophen & - & 5 & 18 \\
\hline Glucosamine/chondroitin & - & 1 & 4 \\
\hline Opioids & - & 1 & 4 \\
\hline $\begin{array}{l}\text { *Frequency was divided by total numb } \\
{ }^{\dagger} \text { Kellgren-Lawrence Grading Systen } \\
\text { Radiological assessment of osteo-art } \\
\text { 494-502. [PMID: 13498604]). } \\
{ }^{\ddagger} \text { Numbers do not add up to } 100 \text { becau } \\
\text { some took multiple medications. } \\
\text { II = only marginal osteophytes apparent } \\
\text { space narrowing apparent in radiograph } \\
\text { in tibiofemoral compartment apparent ir }\end{array}$ & $\begin{array}{l}\text { r of subjects }(N \\
\text { (Source: Kel } \\
\text { aritis. Ann Rhe } \\
\text { ise not all subje } \\
\text { in radiographs, I } \\
\text { s, IV = complete } \\
\text { radiographs, SL }\end{array}$ & $\begin{array}{l}\text { 28) to calculate } \\
\text { gren JH, Lawre } \\
\text { m Dis. 1957;16( } \\
\text { ts took medicat } \\
\text { I = mild-to-mode } \\
\text { loss of medial jo } \\
\text { = standard devia }\end{array}$ & $\begin{array}{l}\text { ercent. } \\
\text { ice JS. } \\
\text { ): } \\
\text { ons and } \\
\text { te joint } \\
\text { t space } \\
\text { on. }\end{array}$ \\
\hline
\end{tabular}




\section{Description of Insole and Footwear}

To control for the effects of footwear, we fitted subjects with comfortable, lightweight shock-absorbing shoes (New Balance 833, New Balance Athletic Shoe, Inc, Boston, Massachusetts) that would accommodate the insoles (RJ Industries, Chicago, Illinois). Both full-length lateral-wedge insoles and neutral-wedge insoles were constructed from a custom cork composite similar to Thermocork $^{\mathrm{TM}}$ (Aetrex Worldwide, Inc, Teaneck, New Jersey) with a density of 60 durometers. The material was engineered to provide shock absorption and high resistance to compressive deformation. The insoles were manufactured with a mediolateral incline of $4^{\circ}$ for the lateral-wedge insole and $0^{\circ}$ for the neutral-wedge insole. Both the lateral- and neutral-wedge insoles were cut to fit the individual shoe, designed with peel-and-stick selfadhesive, and placed under the removable insert that came in the shoes.

\section{Procedures}

The baseline assessment consisted of the WOMAC, a validated and disease-specific questionnaire that separately addresses severity of joint pain (5 questions), stiffness (2 questions), and physical function limitation (17 questions) experienced during the 24 hours before assessment [18-19]. The VAS version of the WOMAC was used. Assessments of joint pain and stiffness focused on the index knee, unless subject had bilateral pain in which case both knees were considered collectively. When reporting functional limitations, all subjects were asked to consider both knees collectively. Information about analgesic use during the 24 hours before the assessment was also collected (Table 1). Subjects were instructed to begin wearing the walking shoes with the full-length inserts for as many hours a day and as many days of the week as they could tolerate for 4 weeks and continue taking their usual OA pain medication(s) as needed. Assessments performed at the end of 4 weeks included adverse events, analgesic use during the past 24 hours, use of the insert, and the WOMAC.

\section{Data Analysis}

The difference (change) between 4 week postintervention and baseline WOMAC subscale and total scores was calculated. The percent change was calculated as the change divided by the baseline score multiplied by 100 . Negative values represented lower WOMAC scores postintervention, which were considered an improvement. Positive values represented higher scores postintervention, which were considered a decrement. Change and percent change were calculated for each subject for each subscale. Mean and SD were calculated for each WOMAC subscale, change, and percent change at both baseline and 4 weeks postintervention. Baseline and 4 week postintervention WOMAC subscale scores were compared with paired $t$-tests. An $\alpha$ level of 0.05 (two-tailed) was used. We analyzed frequency counts for improvement levels (20\%, 50\%, and 70\%) [20] to determine response to intervention. Subjects were categorized within the three improvement level groups based on whether they had the minimum percent improvement for a group but not the next higher level of percent improvement (i.e., 20\% group: $\geq 20 \%$ but $<50 \%$; $50 \%$ group: $\geq 50 \%$ but $<70 \%$; and $70 \%$ group: $\geq 70 \%$ ) for each subset.

\section{RESULTS}

When comparing the change from baseline to 4 weeks postintervention, we found WOMAC subscale and total scores significantly improved $(p<0.05)$ (Table 2). While the average percent change was highly variable, almost 50 percent (range $=47 \%-53 \%$ ) of the individuals demonstrated at least a 20 percent improvement in the WOMAC subscales (Figure) and more than 10 percent

Table 2.

Mean \pm standard deviation Western Ontario and McMaster Universities (WOMAC) Osteoarthritis Index subscale scores at baseline and 4 weeks postintervention. Data presented as values for each time point, change between time points, and percent change between time points relative to baseline values.

\begin{tabular}{|c|c|c|c|c|c|}
\hline WOMAC Subscale & Baseline & Postintervention & Change* & Percent Change $^{\dagger}$ & $p$-Value \\
\hline Pain & $172.3 \pm 95.0$ & $137.0 \pm 97.8$ & $-35.3 \pm 83.1$ & $-17.0 \pm 46.9$ & 0.03 \\
\hline Stiffness & $81.7 \pm 56.2$ & $65.5 \pm 49.2$ & $-16.3 \pm 41.4$ & $1.8 \pm 91.8$ & 0.05 \\
\hline Function & $681.2 \pm 329.2$ & $569.4 \pm 392.4$ & $-121.8 \pm 199.3$ & $-18.0 \pm 60.9$ & 0.003 \\
\hline
\end{tabular}

*Change = postintervention - baseline; negative numbers represent improvement and positive numbers represent decrement.

${ }^{\dagger}$ Percent change $=($ [postintervention - baseline $] /$ baseline $) \times 100$. 


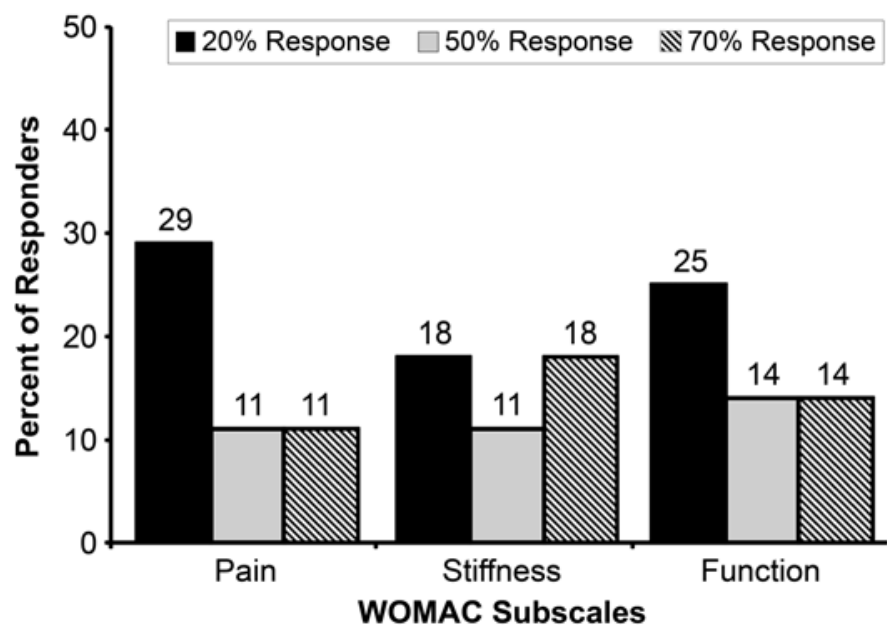

Figure.

Percent of subjects who demonstrated each level of improvement (20\%, $50 \%$, or $70 \%$ ) within each Western Ontario and McMaster Universities (WOMAC) Osteoarthritis Index subscale following intervention.

(range $=11 \%-18 \%$ ) of the individuals reported at least a 70 percent improvement in the WOMAC subscales (Figure).

When evaluating the specific components of the pain subscale, we found that the question about the most challenging activity (going up or down stairs) showed significant improvement (reduction in value postintervention) (Table 3). On this question, 64 percent of the individuals reported at least 20 percent improvement and 7 percent reported at least 70 percent improvement. However, subjects did not demonstrate significant change on any other question $(p>0.05)$.

\section{DISCUSSION}

Simple, inexpensive therapies for the treatment of pain from symptomatic medial compartment knee OA include wearing shock-absorbing footwear, wedge heels, or insoles. The results of our short-term pilot study indicated that subjects experienced a significant decrease in pain, stiffness, and functional impairment when they wore a full-length lateral-wedge insole with an incline of $4^{\circ}$ for the symptomatic limb and a full-length neutralwedge insole for the asymptomatic limb in their shockabsorbing walking shoes. All subjects tolerated their orthoses well and wore the insoles daily. Subjects experienced decreased pain primarily during stair-climbing activities rather than while walking on a flat surface, standing, lying, or sitting. The combination of lateralwedge insoles and shock-absorbing shoes appeared to be most efficacious for tasks that reflected greater knee compressive forces, such as stair-climbing activities [21].

Salsich et al. observed that individuals with patellofemoral pain had reduced peak knee extensor moments during stair-climbing activities. They suggested that quadriceps avoidance is used to reduce knee joint reaction forces, a compensatory strategy that is commonly observed in individuals with knee OA [22]. Fisher et al. reported that subjects with knee OA predominately lacked knee extensor moments due to weak quadriceps [23]. Quadriceps weakness has been well documented in subjects with OA [24]. Messier suggested that the quadriceps avoidance pattern was used by subjects with knee OA who had limited knee flexion so they could avoid any knee flexion that would require eccentric control via the quadriceps muscles [25]. Eccentric contraction of the quadriceps muscles requires more control and also tends to increase the compressive forces on the knee joint [26]. Stair climbing results in a significantly greater knee flexion angle, which in turn results in a greater knee extensor moment than level walking [27] and suggests why, during

Table 3.

Mean \pm standard deviation for individual questions on Western Ontario and McMaster Universities (WOMAC) Osteoarthritis Index pain subscale at baseline and 4 weeks postintervention. Data presented as values for each time point, change between time points, and percent change between time points relative to baseline values.

\begin{tabular}{|c|c|c|c|c|c|}
\hline Pain Subscale Question & Baseline & Postintervention & Change* $^{*}$ & Percent Change $^{\dagger}$ & p-Value \\
\hline Walking on Flat Surface & $34.9 \pm 27.8$ & $26.9 \pm 21.7$ & $-8.0 \pm 24.5$ & $15.4 \pm 136.9$ & 0.096 \\
\hline Going up or Down Stairs & $55.1 \pm 24.8$ & $41.4 \pm 25.4$ & $-13.6 \pm 19.6$ & $-23.2 \pm 42.4$ & 0.0001 \\
\hline At Night While in Bed & $28.8 \pm 26.6$ & $21.3 \pm 23.0$ & $-7.5 \pm 22.2$ & $-5.3 \pm 91.6$ & 0.084 \\
\hline Standing Upright & $27.4 \pm 19.9$ & $26.9 \pm 22.1$ & $-0.5 \pm 16.0$ & $27.9 \pm 121.5$ & 0.870 \\
\hline
\end{tabular}

${ }^{*}$ Change $=$ postintervention - baseline; negative numbers represent improvement and positive numbers represent decrement.

${ }^{\dagger}$ Percent change $=($ [postintervention - baseline $] /$ baseline $) \times 100$. 
this short-term study, we found pain reduction in the activity that most challenged the knee musculature.

While we found short-term significant reductions in all three components of the WOMAC, Pham et al. found no changes in WOMAC pain, joint stiffness, and physical function subscales between those wearing full-length lateral-wedge insoles and those wearing neutral-wedge insoles in patients with medial femorotibial knee OA in a 2-year prospective randomized controlled study [11]. The group wearing the lateral-wedge insoles, however, did have a decrease in NSAID consumption and were more compliant in wearing insoles than the group wearing neutral-wedge insoles, prompting Pham et al. to suggest a beneficial effect from wearing lateral-wedge insoles in medial femorotibial OA [11]. This reduction in NSAID consumption may have biomechanical implications; Hurwitz et al. have demonstrated that subjects with knee OA pain relieved by analgesics continue to have abnormal loading of the knee joint with increases in peak external varus and extension moments [28].

Rubin and Menz studied the efficacy of incorporating a lateral-wedge insole into custom-molded foot orthoses in an uncontrolled pilot study and reported that all 30 patients had achieved some reduction in medial knee OA pain and that 28 patients tolerated their orthoses [29]. Toda and Tsukimura observed clinical and structural improvements at 6-month assessment in subjects who wore a subtalarstrapped lateral-wedge insole [12]. At the 6-month assessment, the subtalar-strapped lateral-wedge insole group demonstrated significantly decreased femorotibial angles, improved VAS scores, and improved Lequesne index scores compared with their baseline assessments, while those who wore the traditional shoe-insert wedge insole did not demonstrate changes [12]. At the 2-year assessment, the significantly decreased femorotibial angles and improved Lequesne index scores remained for those wearing the subtalar-strapped lateral-wedge insole [30]. Toda and Tsukimura suggested that the movement of the talus by the insole may interfere with calcaneal valgus correction and subsequently prevent femorotibial correction [12]. With the subtalar-strapped lateral-wedge insole, decreased femorotibial angles may restrict the progression of degenerative articular cartilage lesions of knee OA [30]. The decreased femorotibial angles may be related to correction of abnormal knee biomechanical loading. Mundermann et al. suggested that patients with more severe OA had greater varus alignment compared with patients with less severe knee OA, which resulted in greater knee adduction moments [30].
Overall, the lateral-wedge insoles appear to be well tolerated. Differences in outcome measure results, however, suggest a variety of factors may interact with use of the lateral-wedge insoles in this population. Our subjects wore lightweight, flexible, cushioned shoes designed for a neutral gait and sized to accommodate the insert. Some of the decrease in knee pain, stiffness, and functional impairment noted by our subjects may be the result of wearing shock-absorbing shoes sized to accommodate the insert. We, however, did not use static or dynamic alignment measures of the knee, ankle, and foot to determine the appropriate degree of incline for each subject. Kerrigan et al. demonstrated that both a $5^{\circ}$ and a $10^{\circ}$ lateral-wedge insole reduced knee external varus moment in patients with knee OA, suggesting that some individuals may benefit from greater degrees of wedge inclination [14].

While all of our subjects wore the insoles daily, Toda et al. suggested that the lateral-wedge insole with subtalar strapping needs to be worn between 5 and 10 hours a day for optimal valgus correction of the femorotibial angle and response to the Lequesne index [31]. Other factors that may contribute to the lack of response to lateral-wedge insoles include individual differences in lower-limb joint anatomy, quadriceps strength, knee proprioception, ligamentous laxity of the knee, and knee height.

\section{CONCLUSIONS}

This pilot study demonstrated that short-term use of full-length lateral-wedge insoles inserted into shockabsorbing walking shoes will decrease pain, stiffness, and functional impairment in patients with symptomatic medial compartment knee OA of varying radiographic severity. Reduction in pain mainly occurred when subjects walked up and down stairs, which suggests biomechanical analyses are needed to determine thresholds of joint reaction forces and moments for restricting the progression of degenerative articular cartilage lesions of knee OA. Wedge insoles inserted into shock-absorbing walking shoes are an inexpensive, well-tolerated treatment for symptomatic medial compartment knee OA.

\section{ACKNOWLEDGMENTS}

We would like to acknowledge the use of the Gait Laboratory at the VA West Los Angeles Healthcare Center, Los Angeles, California. Fabrication and materials for the 
shoe inserts were arranged by American Medical Prosthetics and Orthotics, Van Nuys, California. American Medical Prosthetics and Orthotics did not have any involvement in the study design; data collection, analysis or interpretation; or writing or submission of this article. We would also like to thank Robyn Burgess and Sanghee Hong for their help in collecting and analyzing the data.

This material was based on work supported by the VA Office of Research and Development, Rehabilitation Research and Development Service (grant A3120P).

The authors have declared that no competing interests exist.

\section{REFERENCES}

1. Baliunas AJ, Hurwitz DE, Ryals AB, Karrar A, Case JP, Block JA, Andriacchi TP. Increased knee joint loads during walking are present in subjects with knee osteoarthritis. Osteoarthritis Cartilage. 2002;10(7):573-79. [PMID: 12127838]

2. Sharma L, Cahue S, Song J, Hayes K, Pai YC, Dunlop DD. Physical functioning over three years in knee osteoarthritis: Role of psychosocial, local mechanical, and neuromuscular factors. Arthritis Rheum. 2003;48(12):3359-70. [PMID: 14673987]

3. Jackson BD, Wluka AE, Teichtahl AJ, Morris ME, Cicuttini FM. Reviewing knee osteoarthritis-A biomechanical perspective. J Sci Med Sport. 2004;7(3):347-57. [PMID: 15518300]

4. Johnson F, Leitl S, Waugh W. The distribution of load across the knee. A comparison of static and dynamic measurements. J Bone Joint Surg Br. 1980;62(3):346-49.

[PMID: 7410467]

5. Cerejo R, Dunlop DD, Cahue S, Channin D, Song J, Sharma L. The influence of alignment on risk of knee osteoarthritis progression according to baseline stage of disease. Arthritis Rheum. 2002;46(10):2632-36. [PMID: 12384921]

6. Brouwer RW, Jakma TS, Bierma-Zeinstra SM, Verhagen AP, Verhaar JA. Osteotomy for treating knee osteoarthritis. Cochrane Database Syst Rev. 2005;(1):CD004019. [PMID: 15674926]

7. Jordan KM, Arden NK, Doherty M, Bannwarth B, Bijlsma JW, Dieppe P, Gunther K, Hauselmann H, Herrero-Beaumont G, Kaklamanis P, Lohmander S, Leeb B, Lequesne M, Mazieres B, Martin-Mola E, Pavelka K, Pendleton A, Punzi L, Serni U, Swoboda B, Vergruggen G, ZimmermanGorska I, Dougados M; Standing Committee for International Clinical Studies including Therapeutic Trials ESCISIT. EULAR Recommendations 2003: An evidence based approach to the management of knee osteoarthritis: Report of a Task Force of the Standing Committee for
International Clinical Studies Including Therapeutic Trials (ESCISIT). Ann Rheum Dis. 2003;62(12):1145-55.

[PMID: 14644851]

8. Recommendations for the medical management of osteoarthritis of the hip and knee: 2000 update. American College of Rheumatology Subcommittee on Osteoarthritis Guidelines. Arthritis Rheum. 2000;43(9):1905-15. [PMID: 11014340$]$

9. Brouwer RW, Jakma TS, Verhagen AP, Verhaar JA, Bierma-Zeinstra SM. Braces and orthoses for treating osteoarthritis of the knee. Cochrane Database Syst Rev. 2005;(1):CD004020. [PMID: 15674927]

10. Marks R, Penton L. Are foot orthotics efficacious for treating painful medial compartment knee osteoarthritis? A review of the literature. Int J Clin Pract. 2004;58(1):49-57. [PMID: 14994971]

11. Pham T, Mailefert JF, Hudry C, Kieffert P, Bourgeois P, Lechevalier D, Dougados M. Laterally elevated wedged insoles in the treatment of medial knee osteoarthritis. A twoyear prospective randomized controlled study. Osteoarthritis Cartilage. 2004;12(1):46-55. [PMID: 14697682]

12. Toda Y, Tsukimura N. A six-month followup of a randomized trial comparing the efficacy of a lateral-wedge insole with subtalar strapping and an in-shoe lateral-wedge insole in patients with varus deformity osteoarthritis of the knee. Arthritis Rheum. 2004;50(10):3129-36. [PMID: 15476225]

13. Crenshaw SJ, Pollo FE, Calton EF. Effects of lateralwedged insoles on kinetics at the knee. Clin Orthop Relat Res. 2000;(375):185-92. [PMID: 10853168]

14. Kerrigan DC, Lelas JL, Goggins J, Merriman GJ, Kaplan RJ, Felson DT. Effectiveness of a lateral-wedge insole on knee varus torque in patients with knee osteoarthritis. Arch Phys Med Rehabil. 2002;83(7):889-93. [PMID: 12098144]

15. Kakihana W, Akai M, Nakazawa K, Takashima T, Naito K, Torii S. Effects of laterally wedged insoles on knee and subtalar joint moments. Arch Phys Med Rehabil. 2005; 86(7):1465-71. [PMID: 16003682]

16. Altman R, Asch E, Bloch D, Borenstein K, Brandt K, Christy W, Cooke TD, Greenwald R, Hochberg M, Howell D, Kaplan D, Koopman W, Longley S 3rd, Mankin H, McShane DJ, Medsger T Jr, Meenan R, Mikkelsen W, Moskowitz R, Murphy W, Rothschild B, Segal M, Sokoloff L, Wolfe F. Development of criteria for the classification and reporting of osteoarthritis. Classification of osteoarthritis of the knee. Diagnostic and Therapeutic Criteria Committee of the American Rheumatism Association. Arthritis Rheum. 1986;29(8):1039-49. [PMID: 3741515]

17. Kellgren JH, Lawrence JS. Radiological assessment of osteo-arthritis. Ann Rheum Dis. 1957;16(6):494-502. [PMID: 13498604]

18. McConnell S, Kolopack P, Davis AM. The Western Ontario and McMaster Universities Osteoarthritis Index (WOMAC): A review of its utility and measurement properties. Arthritis Rheum. 2001;45(5):453-61. [PMID: 11642645] 
19. Bellamy N. WOMAC Osteoarthritis Index. A user's guide. Ontario (Canada): University of Western Ontario; 1996.

20. Bellamy N, Bell MJ, Goldsmith CH, Pericak D, Walker V, Raynauld JP, Torrance GW, Tugwell P, Polisson R. Evaluation of WOMAC 20, 50, 70 response criteria in patients treated with hylan G-F 20 for knee osteoarthritis. Ann Rheum Dis. 2005;64(6):881-85. [PMID: 15564311]

21. Luepongsak N, Amin S, Krebs D, McGibbon CE, Felson D. The contribution of type of daily activity to loading across the hip and knee joints in the elderly. Osteoarthritis Cartilage. 2002;10(5):353-59. [PMID: 12027536$]$

22. Salsich GB, Brechter JH, Powers CM. Lower extremity kinetics during stair ambulation in patients with and without patellofemoral pain. Clin Biomech (Bristol, Avon). 2001;16(10):906-12. [PMID: 11733129]

23. Fisher NM, White SC, Yack HJ, Smolinski RJ, Pendergast DR. Muscle function and gait in patients with knee osteoarthritis before and after muscle rehabilitation. Disabil Rehabil. 1997;19(2):47-55. [PMID: 9058029]

24. Slemenda C, Brandt KD, Heilman DK, Mazzuca S, Braunstein EM, Katz BP, Wolinsky FD. Quadriceps weakness and osteoarthritis of the knee. Ann Intern Med. 1997; 127(2):97-104. [PMID: 9230035]

25. Messier SP. Osteoarthritis of the knee and associated factors of age and obesity: Effects on gait. Med Sci Sports. 1994;26(12):1446-52. [PMID: 7869877]

26. Sharma L, Hurwitz DE, Thonar EJ, Sum JA, Lenz ME, Dunlop DD, Schnitzer TJ, Kirwan-Mellis G, Andriacchi TP. Knee adduction moment, serum hyaluronan level, and disease severity in medial tibiofemoral osteoarthritis. Arthritis Rheum. 1998;41(7):1233-40. [PMID: 9663481]

27. Nadeau S, McFadyen BJ, Malouin F. Frontal and sagittal plane analyses of the stair climbing task in healthy adults aged over 40 years: What are the challenges compared to level walking? Clin Biomech (Bristol, Avon). 2003;18(10): 950-59. [PMID: 14580839]

28. Hurwitz DE, Ryals AR, Block JA, Sharma L, Schnitzer TJ, Andriacchi TP. Knee pain and joint loading in subjects with osteoarthritis of the knee. J Orthop Res. 2000;18(4):572-79. [PMID: 11052493]

29. Rubin R, Menz HB. Use of laterally wedged custom foot orthoses to reduce pain associated with medial knee osteoarthritis: A preliminary investigation. J Am Podiatr Med Assoc. 2005;95(4):347-52. [PMID: 16037549]

30. Mundermann A, Dyrby CO, Andriacchi TP. Secondary gait changes in patients with medial compartment knee osteoarthritis: Increased load at the ankle, knee, and hip during walking. Arthritis Rheum. 2005;52(9):2835-44.

[PMID: 16145666]

31. Toda Y, Tsukimura N, Segal N. An optimal duration of daily wear for an insole with subtalar strapping in patients with varus deformity osteoarthritis of the knee. Osteoarthritis Cartilage. 2005;13(4):353-60. [PMID: 15780649]

Submitted for publication October 18, 2005. Accepted in revised form April 4, 2006. 